\title{
Antibody in sera of patients infected with Trichomonas vaginalis is to trichomonad proteinases
}

\author{
J F Alderete, E Newton, C Dennis, K A Neale
}

\begin{abstract}
Background-A recent report demonstrated the immunogenic character of the cysteine proteinases of Trichomonas vaginalis. It was of interest, therefore, to examine for the presence of serum anti-proteinase antibody among patients with trichomoniasis.

Methods-An immunoprecipitation assay was used involving protein A-bearing Staphylococcus aureus first coated with the IgG fraction of goat anti-human Ig and then mixed with individual sera of patients to bind human antibody. These antibody-coated bacteria were then added to detergent extracts of $T$ vaginalis. Bound immune complexes on $S$ aureus were washed and solubilised for electrophoretic analysis on acrylamide copolymerised with gelatin for detection of proteinase activity.

Results-Sera from patients $(50 / 50)$, but none from sera of normal, uninfected women, possessed IgG to numerous trichomonad cysteine proteinases. The presence of this serum antiproteinase antibody disappeared after drug treatment and cure of patients of the $T$ vaginalis infection.

Conclusions-The commonality of the antiproteinase antibody in the sera of patients with trichomoniasis provided evidence for the expression of the same repertoire of parasite proteinases during infection. These observations have important implications for the in vivo relevance of the proteinases and indicate that strategies to use a specific serum antibody response for diagnosis of this infection may be possible.
\end{abstract}

\section{Introduction}

Trichomonas vaginalis is a protozoan which causes a non-self-limiting sexually transmitted disease that affects mostly women. The absence of any evidence indicating host immunity of this agent, even after

Departments of Obstetrics and Gynecology, and Microbiology, The University of Texas Health Center, San Antonio, Texas 78284-7758, USA

J F Alderete, E Newton, C Dennis, K A Neale repeated infections, is intriguing in the light of the presence of antibodies reactive with trichomonad immunogens in vaginal washes and sera of patients with trichomoniasis. ${ }^{1-5}$

More recently, the cysteine proteinases of $T$ vaginalis have received attention ${ }^{6-10}$ for their possible role in participating in a variety of important virulence properties, such as cytadherence, ${ }^{6}$ host cytopathogenicity, ${ }^{611-13}$ and nutrient acquisition. ${ }^{11}{ }^{14}$ The complexity of the total repertoire of cysteine proteinases was also demonstrated, ${ }^{9}$ as evidenced by the total number and differential expression of proteinases during in vivo and invitro growth of isolates. ${ }^{9}$

Because a report indicated that proteinases of $T$ vaginalis are shed or released during in vitro growth and multiplication ${ }^{8}$ and the multiple roles that the proteinases might have in the host-parasite interaction, ${ }^{611-14}$ it was important to examine for their expression during infections. To accomplish this we evaluated sera from patients for the presence of antibodies to trichomonad proteinases.

This report describes for the first time the presence of antibodies to proteinases in the sera of $T$ vaginalisinfected patients. All sera from patients with trichomoniasis had anti-proteinase immunoglobulin G (IgG) antibody. The short-lived nature of this serum anti-proteinase response was also demonstrated in patients who were treated for trichomoniasis after diagnosis.

\section{Materials and methods \\ Isolates and growth}

Isolate NYH $286^{1269}$ was used for all experiments unless otherwise indicated. This isolate consistently gives a total proteinase pattern as described recently. ${ }^{9}$ The synthesis of proteinases among fresh clinical isolates has also been described. ${ }^{9}$ Trichomonads were passaged daily after overnight growth in a complex medium of trypticase-yeast extract-maltose supplemented with heat-inactivated horse serum. ${ }^{15}$

\section{Patients}

Patients with trichomoniasis visited an outpatient clinic in San Antonio, Texas, and infections with $T$ vaginalis were confirmed by both microscopic examination and positive culture. ${ }^{16} 17$ Patient histories were obtained as previously described. ${ }^{17}$ Individuals diagnosed with trichomoniasis were 
treated with metronidazole. Serum was obtained from patients during evaluation and diagnosis as well as one week after treatment, and only sera from patients confirmed by both microscopic detection and culture of parasites were used. Control serum was obtained from women volunteers without a history of sexually-transmitted diseases.

\section{Immunoprecipitation assay and proteinase detection} Immunoprecipitation was performed using $2 \times 10^{6}$ trichomonads solubilised in $200 \mu \mathrm{l}$ of $0.05 \%$ Zwittergent 3-12 (Z3-12) (Calbiochem-Behring Co, La Jolla, CA) prepared in phosphate buffered saline (PBS). ${ }^{19}{ }^{18}$ One hundred $\mu \mathrm{l}$ of $10 \%$ fixed Staphylococcus aureus in PBS containing 0.05\% Z3-12 was incubated with an equal volume of $1: 200$ dilution of the IgG fraction of goat anti-human IgG for up to two hours at $4^{\circ} \mathrm{C}$. Alternatively, $S$ aureus was pretreated with the IgG fraction of rabbit antihuman total Ig. This washed, pretreated bacterial preparation was then incubated with a 1:10 dilution of serum. This $S$ aureus preparation was then used to immunoprecipitate proteinase(s) from Z3-12 detergent extracts of $T$ vaginalis proteins as previously described. ${ }^{2918}$ Solubilisation of $S$ aureus-bound proteinases was by addition of dissolving buffer, as recently described ${ }^{8}$ for substrate electrophoresis using gelatin.

Proteinases were detected by one dimensional electrophoresis using $7 \cdot 5 \%$ acrylamide copolymerised with gelatin as substrate, which was performed as recently described. ${ }^{9}$ Attempts to analyse proteinases by two-dimensional electrophoresis ${ }^{9}$ as accomplished recently were unsuccessful, presumably because of the small amounts of proteinases being precipitated by the patient serum antibody.

\section{Results}

We tested for the presence of antibody to proteinases in the sera of patients. The figure shows the results of typical immunoprecipitation experiments. Onedimensional electrophoretic analysis for proteinases using gelatin as substrate revealed that all sera had IgG to proteinase, as evidenced by the patterns of proteinase reactivity. Only quantitative differences, based on the intensities of the proteinase bands, were observed in the sera of 50 patients with trichomoniasis which were tested. Control sera from women without any history of trichomoniasis ${ }^{17}$ did not possess any IgG that precipitated any proteinases. Lastly, no differences were seen when $S$ aureus was pretreated with either anti-human IgG or antihuman Ig, indicating that IgG was the predominant immunoglobulin in serum toward proteinases.

We also tested four patients from whom sera was obtained after one week following treatment with metronidazole. At this time the patient tested

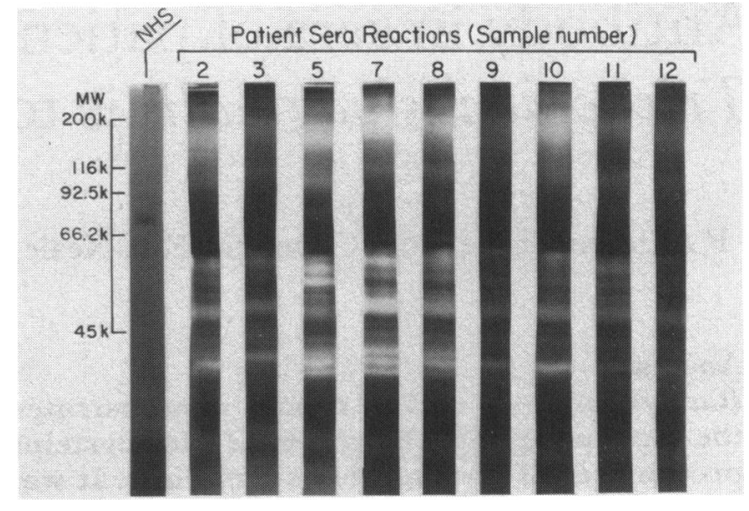

Demonstration of antibody in sera of patients with trichomoniasis immunoreactive with proteinases in trichomonal detergent extracts. No similar binding of proteinases was seen for $S$ aureus pretreated with a pooled preparation of normal sera from individuals without a history of sexually transmitted diseases (NHS).

negative for $T$ vaginalis by wet mount and culture assays. This post-treatment serum of each patient was compared with serum obtained during evaluation and diagnosis, as seen in the figure. Sera obtained after treatment had no antibody to proteinases, as evidenced by no detectable immunoprecipitation of proteinases. These post-treatment sera gave reactions identical with those seen for control sera (NHS) from uninfected women (fig).

\section{Discussion}

The immunogenic nature of Trichomonas vaginalis proteinases was recently demonstrated. ${ }^{9}$ This study now extends these earlier observations and provides evidence, based on the antibody response of patients, of the in vivo relevance of trichomonad proteinases.

Although the trichomonad proteinases were clearly immunogenic among patients with $T$ vaginalis, it should be noted that the titre of antibody was low relative to other trichomonad immunogens. ${ }^{1819}$ This was suggested by the absence of proteinase detection after further dilution of the patient sera and the inability to readily detect the proteinases by twodimensional analysis. ${ }^{9}$ It was recently shown that the genes of trichomonad proteinases are differentially expressed in vivo; ${ }^{9}$ however, electrophoretic analyses of proteinases precipitated by serum antibody indicate that the same repertoire of proteinases are expressed during infection, regardless of the infecting isolate. Thus, it would appear that patients have similar environmental conditions as far as in vivo expression of proteinases is concerned. No correlation was possible with symptomatology and either with presence of antibody to proteinases or with qualitative differences in proteinase patterns. These observations are not necessarily surprising, since they are consistent with the numerous reports that 
indicate no such relationship between symptomatology and parasite properties exists. ${ }^{20-22}$

The exact in vivo function and role of the $T$ vaginalis proteinases are unknown, and this issue is difficult to address in the absence of a suitable animal model. The proteinases have, however, been shown to produce haemolysis ${ }^{11}$ and have been implicated as mediators of cytopathogenicity in cell culture models. ${ }^{6132324}$ The finding of secretion of numerous proteinases by live trichomonads grown in vitro ${ }^{8}$ might also support the idea that these enzymes can mediate cytopathogenicity, as has been documented for other parasites, ${ }^{25-29}$ and the existence of an antibody response toward proteinases reinforces the view that research is needed on the trichomonad proteinases.

This is the first report showing that the $T$ vaginalis proteinases are expressed during trichomoniasis. The antibody to the proteinases, which may be secreted or released by lysis of organisms during infection, ${ }^{8}$ may represent a host response that limits the extent of cytopathology resulting from proteinases, especially if exacerbation of the disease or parasite numbers increase during or after menstruation as has been suggested. Since trichomoniasis is non-self-limiting, it appears that these serum antibodies confer little protection to an infected host. As no information was available to determine the length of exposure to the parasite prior to the patient seeking medical attention, it was not possible to determine the kinetics of the anti-proteinase antibody response. However, of interest was the short-lived antibody response after drug treatment, as it shows it may be possible to monitor the acute versus chronic nature of trichomoniasis by measuring a specific antibody response. ${ }^{20} 30$ The disappearance of serum antibody to proteinases may allow for future determinations of host $T$ vaginalis infection by simple serology-based assays. ${ }^{31} 32$

In summary, $T$ vaginals has many proteinases that have now been shown to be important in vivo, as suggested earlier..$^{8-11}$ The proteinases are involved in critical events, such as during host parasitism, ${ }^{6}$ acquisition of nutrients, ${ }^{11}{ }^{14}$ and possibly as mediators of pathogenesis. ${ }^{610-122324}$ This knowledge now directs our attention toward development of proteinase inhibitors ${ }^{33}$ to interrupt key biofunctionalities of this parasite.

This study was supported by Public Health Service grant AI-22380 from the National Institute of Allergy and Infectious Diseases and by a grant from the South Texas Vaccine Development Center. The excellent secretarial assistance of Diana Hinojosa is especially acknowledged.

Address for correspondence: Dr John F Alderete, Department of Microbiology, UTHSCSA, 7703
Floyd Curl Dr, San Antonio, Texas 78284-7758, USA.

1 Alderete JF. Enzyme-linked immunosorbent assay for detection of antibody to Trichomonas vaginalis: Use of whole cells and aqueous extract as antigen. Br JVenereal Dis 1984;60:164-70.

2 Alderete JF, Suprun-Brown L, Kasmala L, Smith J, Spence M. Heterogeneity of Trichomonas vaginalis and discrimination among trichomonal isolates and subpopulations by sera of patients and experimentally infected mice. Infect Immun 1985b;49:463-8.

3 Street DA, Taylor-Robinson D, Ackers JP, Hanna NF, McMillan A. Evaluation of an enzyme-linked immunosorbent assay for the detection of antibody to Trichomonas vaginalis in sera and vaginal secretions. $B r J$ Venereal Dis 1982;58:330-3.

$4 \mathrm{Su} \mathrm{KW}$. Antibody to Trichomonas vaginalis in human cervicovaginal secretions. Infect Immun 1982;37:852-7.

5 Alderete JF, Newton E, Dennis C, Engbring J, Neale KA. Vaginal antibody of patients with trichomoniasis is to a prominent surface immunogen of Trichomonas vaginalis. Genitourin Med 1991;67:220-5.

6 Arroyo R, Alderete JF. Trichomonas vaginalis proteinase activity is necessary for parasite cytadherence. Infect Immun 1989;57:2991-7.

7 Lockwood BC, North MJ, Scott KI, Bremner AF, Coombs GH. The use of a highly sensitive electrophoretic method to compare the proteinases of trichomonads. Mol Biochem Parasitol 1987;24:89-95.

8 Lockwood BC, North MJ, Coombs GH. The release of hydrolases from Trichomonas vaginalis and Tritrichomonas foetus. Molec Biochem Parasitol 1988;30:135-42.

9 Neale KA, Alderete JF. Analysis of the proteinases of representative Trichomonas vaginalis isolates. Infect Immun 1990;58:157-62.

10 North MJ, Mottram JC, Coombs GH. Cysteine proteinases of parasitic protozoa. Parasitology Today 1990;6:270-5.

11 Dailey DC, Chang TH, Alderete JF. Characterization of a hemolysin of Trichomonas vaginalis. Parasitology 1990;101: 171-5.

12 Kreiger JN, Poisson MA, Rein MF. Beta-hemolytic activity of Trichomonas vaginalis correlates with virulence. Infect Immun 1983;41:1291-5.

13 Pindak FF, Gardner WA, Jr, de Pindak MM. Growth and cytopathogenicity of Trichomonas vaginalis in tissue cultures. J Clin Microbiol 1986;23:672-8.

14 Lehker MW, Chang TH, Dailey DC, Alderete JF. Specific erythrocyte binding is an additional nutrient acquisition system for Trichomonas vaginalis. J Exp Med 1990;171: 2165-70.

15 Peterson KM, Alderete JF. Host plasma proteins on the surface of pathogenic Trichomonas vaginalis. Infect Immun 1982;37: 755-62.

16 Spence MR, Hollander DH, Smith J, McCaig L, Sewell D, Brockman M. The clinical and laboratory diagnosis of Trichomonas vaginalis infection. Sex Trans Dis 1980;7:168-72.

17 Alderete JF, Demeš $\mathrm{P}$, Gombošova $\mathrm{A}$, et al. Phenotype and protein/epitope phenotypic variation among fresh isolates of Trichomonas vaginalis. Infect Immun 1987;55:1037-41.

18 Alderete JF. Identification of immunogenic and antibody-binding proteins on the membrane of pathogenic Trichomonas vaginalis. Infect Immun 1983;40:284-91.

19 Alderete JF, Suprun-Brown L, Kasmala L. Mononoclonal antibody to a major surface glycoprotein immunogen differentiates isolates and subpopulations of Trichomonas vaginalis. Infect Immun 1986;52:70-5.

20 Kreiger JN, Wolner-Hanssen P, Stevens C, Holmes KK. Characteristics of Trichomonas vaginalis isolates from women with and without colpitis macularis. J Infect Dis 1990; 161:307-11.

21 Schaaf VM, Perez-Stable EJ, Borchardt K. The limited value of symptoms and signs in the diagnosis of vaginal infections. Arch Intern Med 1990;150:1929-33.

22 Spence MR, Hollander DH, Smith J, McCaig L, Sewell D, Brockman $M$. The clinical and laboratory diagnosis of Trichomonas vaginalis infection. Sex Trans Dis 1980;7:168-72.

23 Alderete JF, Pearlman E. Pathogenic Trichomonas vaginalis cytotoxicity to cell culture monolayers. $\mathrm{Br} J$ Venereal Dis 1984;60:99-105.

24 Kreiger JN, Ravdin JI, Rein MF. Contact-dependent cytopathogenic mechanisms of Trichomonas vaginalis. Infect Immun 1985;50:778-86. 
25 Borg M, Rüchel R. Expression of extracellular acid proteinase by proteolytic Candida spp during experimental infection of oral mucosa. Infect Immun 1988;56:626-31.

26 Cassone A, de Bernadis F, Mondello F, Ceddia T, Agatensi L. Evidence for a correlation between proteinase secretion and vulvovaginal candidosis. J Infect Dis 1987;156:777-83.

27 McKerrow JH, Pino-Heiss S, Lindquist R, Werb Z. Purification and characterization of an elastinolytic proteinase secreted by cercariae of Schistosoma mansoni. J Biol Chem 1985;260: 3703-7.

28 Reed SL, Keene WE, McKerrow JH. Thiol proteinase expression and pathogenicity of Entamoeba histolytica. J Clin Microbiol 1989;27:2772-7.

29 Schulte $W$, Scholze $H$. Action of the major protease from Entamoeba histolytica on proteins of the extracellular matrix. $J$ Protozool 1989;36:538-43.
30 Masson PL, Heremans JF, Ferin J. Clinical importance of the biochemical changes in the female genital tract. I. Studies on the proteins of cervical mucus. Int J Fertil 1969;14:1-7.

31 Chappell CL, Hackel J, Davis AH. Cloned Schistosoma mansoni proteinase (hemoglobinase) as a putative serodiagnostic reagent. J Clin Microbiol 1989;27:196-8.

32 MacDonald F, Odds FC. Inducible proteinase of Candida albicans in diagnostic serology and in the pathogenesis of systemic candidosis. J Med Microbiol 1980;13:423-35.

33 Björck L, Ákesson P, Bohus M, et al. Bacterial growth blocked by a synthetic peptide based on the structure of a human proteinase inhibitor. Nature 1989;337:385-6.

Accepted for publication 27 March 1991 